\title{
Isolamento de Rickettsia em cultura de células vero
}

\author{
Isolation of Rickettsia in vero cell culture
}

\author{
Heloisa Helena Barbosa Melles', Silvia Colombo e Elba Regina Sampaio de Lemos ${ }^{2}$
}

\begin{abstract}
Resumo Embora o diagnóstico da febre maculosa baseie-se em sinais e sintomas característicos, o mesmo requer confirmação laboratorial, pois existem alguns diagnósticos diferenciais possíveis como meningococcemia, leptospirose, infecção por enterovírus e febre tifóide. A confirmação laboratorial pode ser feita através da pesquisa de anticorpos específicos, possível somente alguns dias após o aparecimento da doença, através do isolamento do agente em amostras de sangue elou biópsia de pele, e ainda, de amostras de carrapatos coletados do paciente ou de animais reservatório. O isolamento a partir de sangue ou biópsia de pele resulta em diagnóstico precoce da doença, pois na fase de rickettsemia ainda não há anticorpos detectáveis no sangue. Assim, com o objetivo de facilitar o diagnóstico precoce da febre maculosa, estabelecemos um método de isolamento de rickettsia em cultura de células vero. Para a padronização foi inoculada amostra padrão de Rickettsia rickettsii, cepa Sheyla Smith, cedida pelo CDC. A identificação foi feita através da reação de imunofluorescência indireta. A presença de microrganismos verdes fluorescentes visualizados no interior do citoplasma das células caracterizou o crescimento do agente. Posteriormente, a metodologia foi confirmada pelo isolamento do agente da febre maculosa em amostras de biópsia de pele de paciente proveniente de área endêmica no Estado de São Paulo, bem como, de amostras de carrapato do gênero Amblyomma, considerado o reservatório e transmissor da doença no Brasil.
\end{abstract}

Palavras-chaves: Rickettsia rickettsii. Rickettsia. Isolamento. Células vero. Febre maculosa.

\begin{abstract}
The diagnosis of spotted fever is based on characteristic signs and symptoms but requires laboratorial confirmation because of the possible differencial diagnosis from other diseases like leptospirosis, enterovirosis, meningococcemia and tiphoid fever. Laboratorial confirmation may be done by detection of specific antibodies which is possible only 5-10 days after the onset of the symptoms or by the isolation of Rickettsiae from blood and/or skin biopsy and from ticks collected in the patient or in the animal reservoir. The isolation of Rickettsiae from blood or skin biopsy results in an early diagnosis of spotted fever since in the rickettsiemic phase of the disease there is no detectable level of antibodies in the serum. With the purpose of facilitating the diagnosis of Spotted Fever we have standardized the isolation of Rickettsiae in cell culture by a method that is less time consuming and that reduces the biological risks than isolation in guinea pigs. vero cell cultures were inoculated with the Sheyla Smith strain of Rickettsia rickettsii provided by CDC (Atlanta-USA). The identification was performed by indirect immunofluorescence technique. The presence of green fluorescent organisms characterized the growth of the agent. Ulterior confirmation of the methodology was done by isolation of the spotted fever agent from skin biopsy of a patient from an endemic area and from Amblyomma ticks that are the reservoir and vector of the Brazilian spotted fever.
\end{abstract}

Key-words: Rickettsia rickettsii. Rickettsiae. Brazilian spotted fever. isolation. vero cell culture.

\footnotetext{
1. Serviço de Virologia, Setor de Riquétsias do Instituto Adolfo Lutz, São Paulo, SP; 2. Departamento de Virologia, Instituto Oswaldo Cruz, Rio de Janeiro, RJ, Brasil.

Endereço para correspondência: Drª Heloisa Helena B. Melles. Serviço de Virologia/Instituto Adolfo Lutz. Av. Dr. Arnaldo 355, Cerqueira Cesar, 01246-902 São Paulo, SP, Brasil.

Recebido para publicação em19/1/99.
} 
A febre maculosa brasileira tem como agente etiológico a Rickettsia rickettsii, a mesma responsável pela febre maculosa das Montanhas Rochosas nos Estados Unidos, tendo como vetor o carrapato da espécie Amblyomma cajennense.

São raros os dados disponíveis desta patologia no Estado de São Paulo. Encontra-se na literatura, registro da ocorrência de 53 casos, no período de 1957 a 1974 e outros 10, de 1976 a 1982, todos no Instituto de Infectologia Emílio Ribas. Os casos foram originários de Municípios vizinhos da capital de São Paulo. Em 1985, surgiram as primeiras suspeitas da doença nos Municípios de Pedreira e Jaguariúna, SP. A partir daí, foram realizados alguns estudos, na região, com o objetivo de verificar qual a espécie de carrapato que estaria envolvida na transmissão da doença ${ }^{6}$, bem como determinar a prevalência de infectados e a incidência de casos suspeitos ${ }^{1}$.

Em 1988, foi isolada riquétsia de uma criança de 2 anos com suspeita de febre maculosa, proveniente de Mogi das Cruzes, SP que, caracterizada pelo CDC, revelou tratar-se de $R$. rickettsii e com as características da rickettsia da febre maculosa das Montanhas Rochosas (R Regnery: comunicação pessoal, 1990).

O diagnóstico laboratorial dos casos suspeitos pode ser realizado por reações sorológicas para detecção de anticorpos antirickettsias ou pelo isolamento do agente etiológico a partir de sangue, tecidos post mortem ou de lesões petequiais, ou ainda, pela demonstração imunohistológica da $R$. rickettsii em biópsias de pele das lesões exantemáticas ${ }^{11}$.

O método mais utilizado na tentativa de isolamento de Rickettsia é a inoculação do material biológico em cobaios. No entanto, este método é tão demorado quanto o tempo necessário para o registro da soroconversão, além de possuir grande risco biológico.

Com o objetivo de agilizar e tornar mais segura a prática laboratorial no diagnóstico da febre maculosa, foi padronizado um método de crescimento da $R$. rickettsii em cultura de células.

\section{MATERIAL E MÉTODOS}

Cultura celular. Foi utilizada cultura de células vero (rim de macaco verde africano) em monocamadas sobre lamínulas circulares de $12 \mathrm{~mm}$ de diâmetro, mantidas em Meio Mínimo de Eagle (MEM) por 24 a 48 horas. As culturas celulares foram fornecidas pela Seção de Culturas Celulares do Instituto Adolfo Lutz.

Cultivo. 1. Rickettsia padrão. Foi utilizada amostra padrão de $R$. rickettsii cepa Sheyla Smith, cedida pelo CDC. Foram feitas diluições da amostra a 1:10, 1:100 e 1:1000 em tampão fosfato (PBS) pH 7,6. De cada uma das diluições foram inoculados $0,2 \mathrm{ml}$ em 6 tubos de cultura com células confluentes. Os tubos foram centrifugados a $700 \mathrm{xg}$, por 1 hora, a $22^{\circ} \mathrm{C}$. O inóculo foi removido e as preparações acrescidas de MEM suplementado com 3 e $5 \%$ de soro fetal bovino (SFB), $10 \mu \mathrm{g} / \mathrm{ml}$ de gentamicina, $10 \mu \mathrm{g} / \mathrm{ml}$ de vancomicina e $2,5 \mu \mathrm{g} / \mathrm{ml}$ de amphotericina $B$, foram incubadas a $33^{\circ} \mathrm{C}$, por 5 dias $^{7}$.

2. Biópsia de pele. Foi colhida amostra de lesão petequial de paciente com suspeita de febre maculosa, proveniente de região endêmica do Estado de São Paulo. Da amostra de biópsia de pele colhida em $1,5 \mathrm{ml}$ de $\mathrm{BHI}$ (Brain Heart Infusion), foi feito um triturado com pó de vidro estéril, centrifugado a $700 \times$ g por 10 minutos a $0^{\circ} \mathrm{C}$. Do sobrenadante, foi inoculado $0,2 \mathrm{ml} \mathrm{em}$ 6 tubos de cultura de células conforme descrito acima.

3. Carrapatos. Foram coletados carrapatos de capivara (Hydrochaeris hydrochaeris) da mesma região endêmica. Após lavagem e desinfecção com solução de peróxido de hidrogênio a $3 \%$, solução de formaldeído a $10 \%$, álcool $70 \%$ e água destilada estéril, três carrapatos da espécie Amblyomma cooperi foram triturados com pó de vidro, obedecendo os mesmos critérios acima. As preparações foram estocadas em tubos contendo solução de Snyder, a $-70^{\circ} \mathrm{C}$ até o momento da inoculação ${ }^{9}$, que foi realizada conforme descrito para a biópsia de pele.

Imunofluorescência para detecção de Rickettsia: a detecção do crescimento bacteriano nas culturas de célula inoculadas com a amostra padrão, a biópsia de pele e o triturado de carrapato foi realizada por imunofluorescência indireta (IFI) utilizando a lamínula de um dos tubos inoculados com 3 e $5 \%$ de SFB. As lamínulas foram fixadas com acetona gelada por 20 minutos, secas à temperatura ambiente quando foram adicionados $25 \mu \mathrm{l}$ de soro humano imune para $R$. rickettsii. Após incubação a $37^{\circ} \mathrm{C}$ 
por $30 \mathrm{~min}$, as lamínulas foram lavadas com PBS $\mathrm{pH} 7,6$ e adicionado $25 \mu \mathrm{l}$ de soro antiimunoglobulina humana conjugada com fluoresceína e incubadas a $37^{\circ} \mathrm{C}$ por $30 \mathrm{~min}$. As lamínulas foram novamente lavadas com PBS, montadas com glicerina $90 \%$ e examinadas em microscópio de fluorescência Nikon com aumento de 400x. O resultado foi considerado positivo, quando se observou a presença de microrganismos verdes fluorescentes semelhantes a rickettsias nas células ${ }^{7}$.

\section{RESULTADOS}

A presença de rickettsia do grupo da febre maculosa, mantida e isolada em cultura de células, foi verificada pela reação de imunofluorescência indireta identificando microrganismos na forma de bactéria intracelular citoplasmática, incluindo algumas intranucleares. Levou-se em consideração a intensidade de fluorescência de 4+, nos tubos inoculados com $5 \%$ de SFB.

Observando as culturas da amostra padrão nas diluições 1:10, 1:100 e 1:1000, verificamos que nas culturas mantidas com MEM suplementado

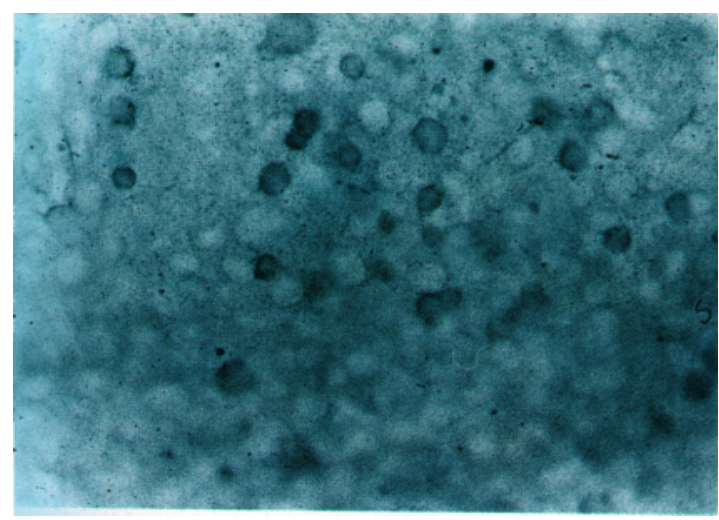

Figura 1 - Cultura de células vero não infectadas. Imunofluorescência 400x.

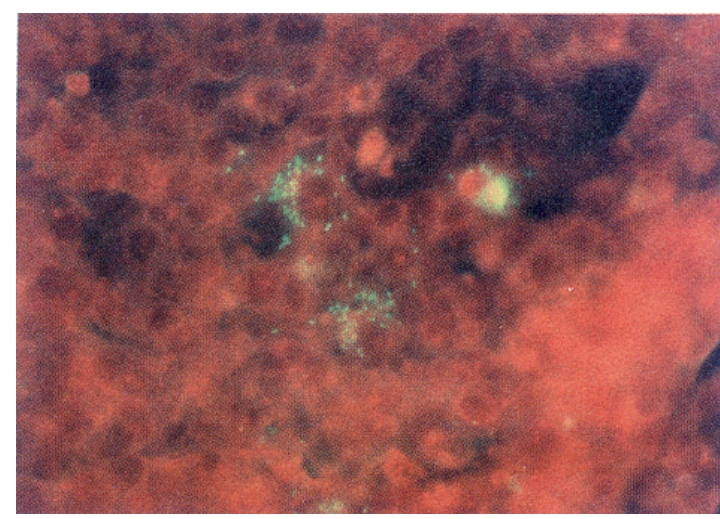

Figura 3 - Cultura de células vero infectadas com Rickettsia isolada de amostra de biópsia de pele de caso suspeito de febre maculosa. Imunofluorescência 400x. com $5 \%$ de SFB houve crescimento de maior número de microrganismos do que naquelas mantidas com 3\% de SFB. Esta verificação se deu tanto nas preparações com a cultura da amostra padrão como para as amostras suspeitas. Constatado o aumento da sensibilidade da técnica com a adição de $5 \%$ de SFB ao meio de cultura e a sua reprodutividade, optamos por adotar esta modificação na concentração do SFB como rotina na tentativa de isolamento de rickettsia dos materiais biológicos enviados ao IAL para diagnóstico (Figuras 1, 2, 3 e 4).

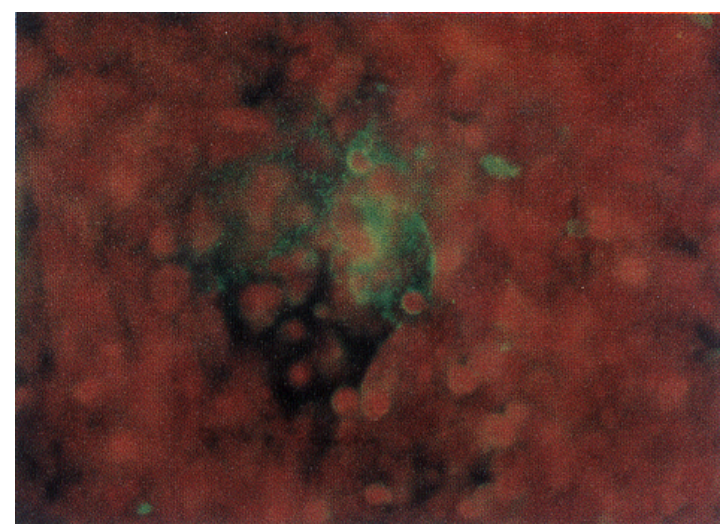

Figura 2 - Cultura de células vero inoculadas com amostra padrão de Rickettsia rickettsii. Imunofluorescência 400x.

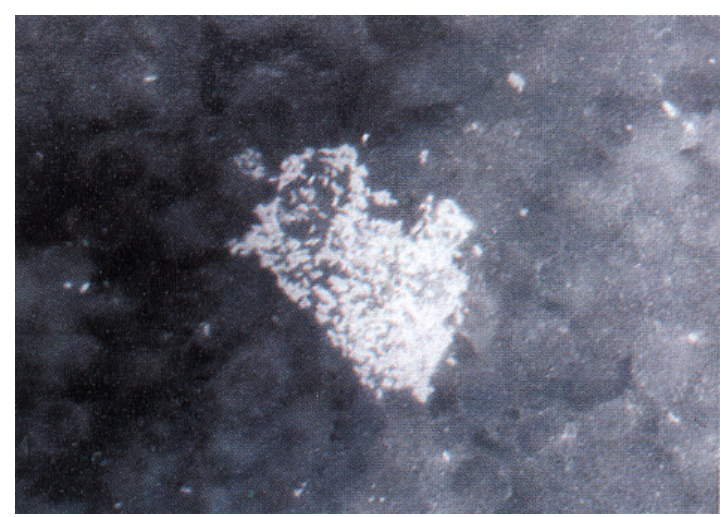

Figura 4 - Cultura de células vero infectadas com Rickettsia isolada de carrapato da espécie Amblyomma cooperi. Imunofluorescência 400x. 


\section{DISCUSSÃO}

Nos casos de febre maculosa clássica, quando não se aplica a terapia adequada, o óbito geralmente ocorre de 8 a 15 dias após o aparecimento dos sintomas, podendo, ainda, ocorrer precocemente, do $1^{\circ}$ ao $5^{\circ}$ dia do início do quadro, nas formas fulminantes, dificultando assim o diagnóstico ${ }^{4}$. O diagnóstico de certeza da febre maculosa é de fundamental importância e deve estar associado ao conhecimento dos antecedentes epidemiológicos e procedência do caso suspeito, pois os sintomas podem ser compatíveis com outras infecções como leptospirose, meningococcemia, infecção por enterovírus, entre outras doenças infecciosas. A suspeita clínica pode facilmente ser confirmada com exames laboratoriais específicos das amostras biológicas colhidas de forma adequada. A reação de imunofluorescência indireta para detecção de anticorpos séricos com uma sensibilidade de 94 a $100 \%$ e especificidade de $100 \%$, tem sido preconizada como método standard para o diagnóstico laboratorial da febre maculosa ${ }^{2}$. Uma única amostra de soro com título de lgG $\geq 64$ é considerada positiva ${ }^{19}$.

O uso de metodologia que leve ao diagnóstico etiológico da febre maculosa, além da confirmação da suspeita clínica, permite a identificação de áreas endêmicas da doença. $O$ isolamento de rickettsia a partir de sangue ou biópsia de pele resulta, de certa forma, em diagnóstico precoce da doença, pois na fase de rickettsemia, ainda não há anticorpos detectáveis no sangue (anticorpos fluorescentes somente aparecem em torno do $5^{\circ}-6^{\circ}$ dia $)^{3}$. Numa única amostra colhida muito cedo, ainda na fase aguda da doença, ou seja, com menos de 5 dias após o aparecimento dos sintomas, anticorpos detectáveis estão ausentes ou em títulos menores que o limite de positividade $(1: 64)^{1} 90$ que não permite a confirmação laboratorial da suspeita clínica.

Considera-se de grande importância a coleta de material para os procedimentos da cultura no isolamento de rickettsia, principalmente levando em conta o risco de óbito do paciente.

Em trabalho anterior verificamos que a amostra de biópsia de pele colhida em torno do $8^{\circ}$ dia de doença, é o material clínico mais efetivo para isolamento, quando comparado com coágulo sanguíneo que pode resultar em negatividade em decorrência da presença de anticorpos no sangue durante esse período ${ }^{8}$.

Considerando-se que os sintomas iniciais da febre maculosa são freqüentemente inespecíficos, podendo alguns pacientes evoluírem sem exantemas é pertinente a busca de novas metodologias mais sensíveis e com menos risco biológico, como os de biologia molecular (PCR), que possam substituir o isolamento, o qual permite a confirmação do caso clínico dentro de um período de 5 dias ${ }^{10}$.

\section{AGRADECIMENTOS}

À Lina Cristina, Técnico de Apoio à Pesquisa Científica e Tecnológica pela colaboração técnica prestada. À Seção de Culturas Celulares do
Instittuto Adolfo Lutz, pelo fornecimento das culturas de células vero.

\section{REFERÊNCIAS BIBLIOGRÁFICAS}

1. Del Guercio VMF, Rocha MMM, Melles HHB, Lima VCL, Pignatt MG. Febre Maculosa no Município de Pedreira, SP, Brasil. Inquérito sorológico. Revista da Sociedade Brasileira de Medicina Tropical 30:47-52, 1997

2. Dumler JS. Laboratory diagnosis of Rickettsial and Ehrlichial infections. Clinical Microbiological Newsletter 15:57-60, 1996.

3. Kaplan JE, Schoenberger LB. The sensitivity of various serological tests in the diagnosis of Rocky Mountain Spotted Fever. American Journal of Tropical Medicine and Hygiene 35: 840-844, 1986.

4. Kirkland KB, Wilkinson WE, Sexton DJ. Therapeutic delay and mortality in cases of Rocky Mountain Spotted Fever. Clinical Infectious Diseases 20:1118-1121,1994.
5. Lemos ERS, Melles HHB, Colombo S, Machado RD, Coura JR, Guimarães MAA, Sanseverino SR, Moura AA. Primary isolation of spotted fever group Rickettsiae from Amblyomma cooperi collected from Hydrochaeris hidrochaeris in Brazil. Memórias do Instituto Oswaldo Cruz 91: 273-275,1996.

6. Lima VLC, Figueiredo AC, Pignatti MG, Modolo M. Febre Maculosa no Município de Pedreira, Estado de São Paulo. Relação entre ocorrência de casos e parasitismo humano por ixodídeos. Revista da Sociedade Brasileira de Medicina Tropical 28:135-137,1995.

7. Marrero M, Raoult D. Centrifugation-shell vial technique for rapid detection of Mediterranean Spotted Fever Rickettsia in blood culture. American Journal of Tropical Medicine and Hygiene 40:197-199, 1989. 
8. Melles HHB, Colombo S, Silva MV. Febre Maculosa: isolamento de Rickettsia em amostra de biópsia de pele. Revista do Instituto de Medicina Tropical de São Paulo 34:37-41,1992.

9. Philip RN, Casper EA. Serotypes of Spotted Fever Group Rickettsiae isolated from Dermacentor andersoni (styles) ticks in Western Montana. American Journal of Tropical Medicine and Hygiene 30: 230-238,1981.
10. Sexton DJ, Kanj SS, Wilson K, Corey GR, Hegarty BC, Levy MG, Breitschwerdt EB. The use of a Polymerase Chain Reaction as a diagnostic test for Rocky Mountain Spotted Fever. American Journal of Tropical Medicine and Hygiene 50:59-63, 1994.

11. Walker DH. Rocky Mountain Spotted Fever: A seasonal alert. Clinical Infectious Diseases 20:1111-1117,1995. 